\title{
Encomio y cortesanía en el Virreinato del Perú: la «Canción real panegírica al marqués de Montesclaros» (1607) de Pedro de Oña’
}

\section{Praise and courtliness in the Viceroyal- ty of Peru: Pedro de Oña's «Canción real panegírica al marqués de Montesclaros» (1607)}

\section{Sarissa Carneiro Araujo}

Pontificia Universidad Católica de Chile

CHILE

scarneir@uc.cl

[Hipogrifo, (issn: 2328-1308), 6.1, 2018, pp. 31-51]

Recibido: 24-01-2017 / Aceptado: 06-02-2017

DOI: http://dx.doi.org/10.13035/H.2018.06.01.04

Resumen. Este artículo analiza la «Canción real panegírica» (1607) de Pedro de Oña al marqués de Montesclaros con foco en dos aspectos relevantes para la producción laudatoria del periodo: la apropiación creativa de la tradición encomiástica y el uso de los códigos de la cortesanía en cuanto adaptación al contexto virreinal del poeta.

Palabras clave. Pedro de Oña; marqués de Montesclaros; poesía virreinal; retórica encomiástica; cortesanía.

Abstract. This article analyzes Pedro de Oña's «Canción real panegírica» (1607) to the marqués de Montesclaros, focusing on two important aspects of the laudatory production of the period: the creative appropriation of encomiastic tradition

1. Agradezco a CONICYT el proyecto FONDECYT no 1141210 que me permitió elaborar este trabajo. Adelanto aquí algunas ideas que expongo con mayor detalle en mi edición de la obra poética de Pedro de Oña dedicada a Juan de Mendoza y Luna (Temblor de Lima y otros poemas al marqués de Montesclaros, virrey del Perú (1607-1615), estudio, edición y notas de Sarissa Carneiro), en preparación. 
and the use of the courtesan codes as an adaptation to the poet's viceregal context.

Keywords. Pedro de Oña; Marqués de Montesclaros; Viceregal poetry; Encomiastic Rhetoric; Courtliness.

\section{INTRODUCCIÓN}

El género encomiástico -en particular, la alabanza de reyes y nobles- constituye una de las facetas más importantes del ejercicio poético durante los siglos XVI y XVII. Este relieve se observa en la producción de casi todos los poetas del periodo, sin excepción de plumas sobresalientes como, por ejemplo, Lope de Vega, Quevedo, Góngora y, en América virreinal, Sor Juana Inés de la Cruz. En El Parnaso español de Quevedo, Clío es la primera musa invocada: sus «elogios y memorias de príncipes y varones ilustres», "al son de la trompeta de la fama»² ocupan el puesto inaugural en la edición de González de Salas. También Góngora ejerció el género con varios poemas dedicados al conde de Salinas, al marqués de Ayamonte y su familia, así como al duque de Feria; y Lope, por su parte, escribió significativos poemas al conde de Lemos, al archiduque Alberto, al duque de Pastrana, al duque de Béjar, al duque de Osuna, entre otros nobles, tal como destacó Ignacio Arellano ${ }^{3}$. En América, el virrey - alter ego del monarca español en Indias- concentró los máximos esfuerzos encomiásticos de los ingenios locales, en un sinfín de circunstancias que motivaron la creación poética, entre las cuales destacaban ciertos hitos como su entrada triunfal al virreinato, momentos significativos de su vida familiar (como, por ejemplo, el nacimiento de un hijo) y la réplica virreinal de celebraciones públicas de la corona, como las exequias de reyes, reinas o príncipes. La entrada de un nuevo virrey era una ocasión especialmente relevante y la producción poética que la acompañaba era copiosa y variada, como atestiguan las relaciones de sucesos, los arcos de triunfo como el Neptuno alegórico de Sor Juana Inés de la Cruz y poemas como la «Canción real panegírica al marqués de Montesclaros» de Pedro de Oña, de la que se ocupa este trabajo.

A pesar del indiscutible alcance de esta poesía encomiástica, muchas veces no se le ha dado la atención que merece, consecuencia - principalmente- del peso de ciertas suspicacias contemporáneas que devienen en lecturas anacrónicas que la juzgan simple manifestación de una adulación interesada. En las últimas décadas, sin embargo, varios estudios han contribuido a rescatar este género e iluminar sus sentidos. Ignacio Arellano destacó las diversas vertientes y matices del mecenazgo (desde la dedicatoria como muestra de deferencia, pleitesía u ofrecimiento de servicios, hasta la modalidad más estricta de secretario o servidor con puesto fijo en nómina) y dio cuenta de la extensión de este fenómeno en los

2. Cito, respectivamente, el título y el último folio de la Musa Clío: «Clío, Musa I, Canta poesías heroicas, esto es, elogios y memorias de príncipes y varones ilustres», El Parnaso español, fol. 5, y «Ansí cantaba Clío, / al son de la trompeta de la fama, / y el numen que la inflama, suspenso aquí, desacordado y frío, / cesó, y entre las flores / los vientos quiso oír murmuradores», fol. 44.

3. Arellano, 1998, p. 339. 
escritores áureos ${ }^{4}$. Victoriano Roncero, por su parte, insistió que las alabanzas a reyes y nobles de Quevedo no deben ser leídas como «meros ejercicios retóricos o encomios a los poderosos, sino que hemos de apreciarlos como testimonios de la ideología política del poeta madrileño», en concreto, de su nostalgia de un pasado glorioso del Imperio y su afán por incitar a Felipe IV a continuar la senda de su bisabuelo 5 . Arellano y Roncero profundizaron en ese cometido al editar la Musa Clío de El Parnaso español, «una poesía - menos estudiada de lo que pide su interés- de un valor indiscutible, como testimonio de una época histórica que nuestro poeta vivió y sintió como pocos de sus contemporáneos» ${ }^{6}$. En el caso de Góngora, varios trabajos han subrayado la importancia de poemas encomiásticos como su «Panegírico al duque de Lerma»; entre otros críticos, Mercedes Blanco observó que en dicho poema Góngora se propuso hispanizar, hacia 1617, un género de la antigüedad latina, imitando a Claudio Claudiano (c.370-c.408 d.C.) y sus panegíricos en verso al emperador Honorio y su valido Estilicón. Jesús Ponce, por su parte, estudió la estela del panegírico gongorino esbozando una tipología del género laudatorio en España entre 1617 y 1705, constituida principalmente por una modalidad amplia (poemas compuestos en octavas reales que siguen el modelo del «Panegírico al duque de Lerma»), una modalidad más breve (vinculada al molde de la canción o la silva), y -los menos frecuentes - tercetos encadenados?

En cuanto a América virreinal, destacan varios estudios sobre las fiestas y la dramática panegírica ${ }^{8}$, pero la poesía encomiástica no ha merecido igual atención en cuanto género independiente. En este artículo, propongo analizar un poema de Pedro de Oña al marqués de Montesclaros como ejemplo significativo de la poesía panegírica criolla en el virreinato del Perú a inicios del siglo XVII. Centraré mi análisis en dos aspectos relevantes no solo para la «Canción real panegírica al marqués de Montesclaros» sino para toda la producción laudatoria del periodo: 1) la apropiación creativa de la larga tradición encomiástica, en cuanto adaptación a las necesidades del contexto histórico del poeta, y 2) el uso de los códigos y estrategias de la cortesanía, que hacía de la alabanza parte sustancial de la interacción con los nobles y soberanos, pilar para la conservación del favor y el mecenazgo. Estos aspectos están íntimamente relacionados, dado que el uso del lenguaje de la cortesanía es, de hecho, una adaptación de la tradición encomiástica al contexto histórico de comienzos del siglo XVII.

\footnotetext{
4. Arellano, 1998, p. 339.

5. Roncero, 2000, p. 262.

6. Arellano y Roncero, 2001, p. 38.

7. Ponce, 2012.

8. Entre otros estudios, pueden consultarse para el virreinato novohispano Buxó 2006 y 2007, así como la extensa producción de Farré sobre el tema, especialmente 2003, 2007 y 2013; para una aproximación general a las fiestas virreinales, ver Mínguez y otros, 2012.
} 
TRADICIÓN ENCOMIÁSTICA Y CORTESANÍA: ALGUNOS ANTECEDENTES

En lo que refiere a la tradición retórica del encomio, el trabajo de Laurent Pernot ha sido fundamental para una mejor comprensión del género y una adecuada apreciación de su potencial político. Por una parte, Pernot hizo una ingente labor de sistematización de la técnica del encomio desde los primeros líricos y autores como Gorgias hasta la segunda sofística (edad de oro de la elocuencia epidíctica). Por otra parte, Pernot rebatió juicios de valor que, desde perspectivas anacrónicas, tildaban el elogio retórico de exhibición vana o estereotipada9. Y subrayó, por el contrario, que el elogio llegó a ser un utillaje mental (unas estructuras, unos estilos y unos sistemas de representación) que permitía reconocer y expresar los valores de una sociedad ${ }^{10}$. En el Alto Imperio, la actividad encomiástica cumplió, según Pernot, una misión de orden político, religioso, poético, de interés para toda la colectividad, debido a su función parenética e ideológica que proclamaba los valores y las concepciones de las élites griegas en la época romana, medio de expresión para su propia afirmación social ${ }^{11}$.

Como subrayaré al analizar la «Canción real panegírica» de Oña, la preceptiva antigua del encomio modeló la poesía encomiástica de comienzos del siglo XVII en el virreinato del Perú, con particular relevancia de los tratados de la época imperial como los atribuidos a Menandro el Rétor (el primer tratado -Menandro I- posterior a 272 d.C., y el segundo -Menandro II- posterior a 283-285 d.C.), que sirvieron luego de guía al poeta de la antigüedad tardía Claudio Claudiano (hacia 370-405 d.C.), cuyos panegíricos poéticos también fueron imitados durante los siglos áureos.

Pero, además, se heredó de la antigüedad, y en especial del periodo imperial, el valor político del panegírico. En el contexto específico que nos concierne, tiempos de ideal monárquico, la política se había retirado al secreto de la corte, a la deliberación entre el príncipe y sus consejeros, y recurrir al género epidíctico era prácticamente la única forma de enunciar un discurso deliberativo, pues todo pasaba, como señaló Marc Fumaroli, por «el filtro de lo atractivo, la alabanza y la belleza lisonjera» ${ }^{12}$.

Esta situación motivó un extraordinario florecimiento de la poesía encomiástica en los siglos XVI y XVII. En un magnífico estudio, Daniel Javitch observó que durante el periodo isabelino la poesía tuvo una función social muy relevante y que ello se sostuvo en una afinidad entre las conductas cortesanas y los procedimientos estilísticos de esa poesía apoyada y estimulada por la corte. Javitch destacó las importantes diferencias entre el orador del Humanismo (idealmente un ciudadano

9. «Mas, face à ces faits, une convergence de jugements, antiques e modernes, ramène l'éloge rhétorique à une production d'apparat, à une exhibition vaine et stéréotypée qui délaisserait tout souci de vérité et d'utilité pour viser l'inexplicable plaisir de l'auditoire. C'est la tradition du dédain et du décri. La dimension encomiastique de la société gréco-romaine d'époque impériale a été occultée par les jugements de valeur» Pernot, 1993, p. 12.

10. Pernot, 1993, p. 793.

11. Pernot, 1993, pp. 793-794

12. Fumaroli, 1999, p. 312 
libre de la república) y el poeta cortesano, al servicio del príncipe o su cercano colaborador ${ }^{13}$ : mientras el primero anhelaba la participación política directa y el fervor sincero, el segundo debía cautivar al príncipe con la belleza, como el que endulza una medicina para un niño delicado ${ }^{14}$. La conducta del cortesano y la poética se unían entonces por varios principios comunes. La sprezzatura -conducta cortesana que aspiraba a que pareciera natural aquello que demandaba considerable esfuerzo y artificio - era una disimulación que guardaba estrecha relación con los modos indirectos del decir poético, fundado en la desproporción respecto del significado literal15. Figura por excelencia de ese decir una cosa y significar otra era la alegoría, reina del arte del periodo. Lo afirmó explícitamente George Puttenham en su The Arte of English Poesie (1589): nadie puede persuadir sin alegoría, figura fundamental para el cortesano y también para los consejeros pues Qui nescit dissimulare nescit regnare ${ }^{16}$. Así establecía Puttenham la relación entre disimulación (cortesana y política) y poesía alegórica. La ambigüedad y la vía indirecta en el lenguaje poético eran aconsejadas también bajo el supuesto de que el placer de la poesía derivaba del modo a través del cual oscurece y aleja el significado ${ }^{17}$. Junto con el ornato y la disimulación, Javitch observa otros rasgos comunes entre poesía y conducta cortesana: el gusto por el ingenio y el juego, por las discrepancias reconciliadas, la habilidad para dar instrucciones de modo más recreativo, todo lo cual permitió a los poetas defender sus capacidades para ejercer un importante rol de consejería en la corte ${ }^{18}$. Esa consejería se infiltraba en los sutiles halagos del encomio: este último se distinguiría de la vil adulación justamente a través de una cuidada atención a la cortesanía (por ejemplo, del principio del decoro) y a la preceptiva encomiástica, en cuanto conjunto de tópicos que impulsaban la emulación de un proyecto ideal de gobierno y virtud ${ }^{19}$. Así, aun cuando en la corte el poeta era apreciado por su talento artístico, fue reconocido en la sociedad como persona cuyos talentos le permitían «ser el único maestro moral tolerado en el centro del poder»²0.

\section{LA «CANCIÓN REAL PANEGÍRICA» A LA LUZ DE LA TRADICIÓN ENCOMIÁSTICA}

Los poemas de Pedro de Oña a Montesclaros acompañaron los hitos más importantes del gobierno del marqués, desde su llegada al virreinato, en 1607, hasta la fastuosa y emotiva celebración de las exequias de la reina Margarita en 1612,

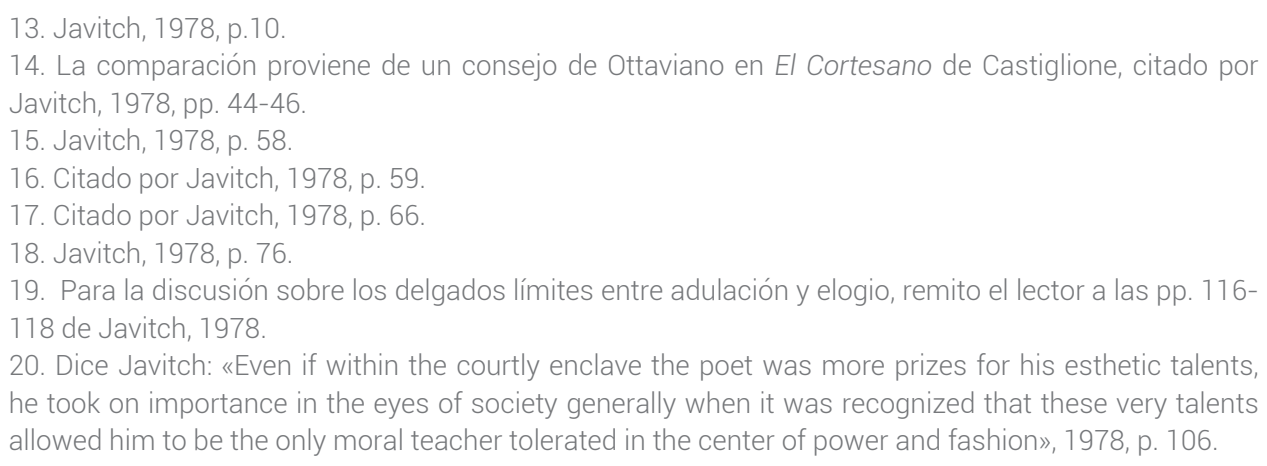


pasando por el complejo momento de reconstrucción de Lima y alrededores, tras el temblor de 1609. Dichos poemas son:

- «Canción real panegírica al excelentísimo señor don Juan de Mendoza y Luna, marqués de Montes Claros, virrey de estos reinos del Pirú, en su venida a ellos», 1607 (incluida en la edición de Temblor de Lima, 1609).

- Temblor de Lima, año de 1609, gobernando el marqués de Montes Claros, virrey excelentísimo..., Lima, Francisco del Canto, 1609.

- «Canción real al Excelentísimo señor don Juan de Mendoza y Luna, marqués de Montes Claros, virrey del Pirú», 1612, incluida en León, Martín de, Relación de las exequias que el excelentísimo señor don Juan de Mendoza y Luna, marqués de Montesclaros, virrey del Pirú, hizo en la muerte de la Reina nuestra señora doña Margarita (1612), Lima, Pedro de Merchán y Calderón, 1613.

En estas composiciones, Pedro de Oña empleó las modalidades más prestigiosas del panegírico poético a inicios del siglo XVII: la canción y el poema largo escrito en octavas reales ${ }^{21}$. La canción petrarquista italiana 22 fue la forma elegida por Oña para alabar al marqués en dos momentos cruciales para cualquier vicesoberano: su entrada triunfal y la celebración de exequias reales en el virreinato.

Respecto de las entradas virreinales, Víctor Mínguez subrayó que en América hispánica estas tuvieron especial significación en cuanto «muestra de aceptación y asentamiento del poder hispano, de pleitesía de sus ciudadanos hacia la monarquía en figura de su más alto representante, de celebración de una nueva etapa de gloria como miembros del Imperio universal y católico» ${ }^{23}$.

21. El poema combina varios géneros y está compuesto por ochenta y tres octavas reales. En un trabajo anterior, presenté un estudio general de Temblor de Lima, al que remito para más detalles: Carneiro, 2016.

22. La canción petrarquista italiana se compone de estancias formadas por un número y una distribución variable de endecasílabos y heptasílabos, con rima consonante. En general, tiene fronte o capo, con tres versos unidos por la rima; eslabón, volta, chiave o llave, que suele ser un heptasílabo que rima con el último verso de la fronte, pero que pertenece sintácticamente a la sirima o coda, que es la tercera parte de la estancia, en la que se incluye el eslabón y al menos un pareado. La «Canción real panegírica» de Oña se compone de once estancias y el habitual commiato (envío de los versos). Respetando la tradición de los poetas italianos, la canción de Oña repite en todas las estancias la rima y el orden de la primera ( 15 versos con rima consonante $A B C A B C C D d E F F E g G)$. La forma de la canción petrarquista sería empleada también por otros poetas cercanos a la Academia Antártica, como por ejemplo la autora anónima de la Epístola de Amarilis a Belardo (más detalles sobre esta epístola y su autora en Vinatea, 2009). 23. Mínguez y otros, 2012, p. 86. Osorio (2001 y 2006) enfatiza, sin embargo, que las celebraciones de exequias tuvieron aun mayor relieve en el virreinato del Perú. En mi edición de la obra poética de Oña a Montesclaros incluyo un estudio de su canción real en el contexto de las exequias de la reina Margarita y confirmo, desde el análisis poético, la afirmación de Osorio realizada desde la historia. 
La entrada de Montesclaros al virreinato peruano fue bastante suntuosa, tal como observó Pilar Latasa: «El cabildo no regateó gastos para que la fiesta se celebrara con todo esplendor», «el virrey entró por un arco triunfal, hizo juramento solemne y recorrió la ciudad montado en un caballo blanco engalanado con terciopelo y chapeado de plata» ${ }^{24}$. El cabildo limeño gastó cerca de 14.000 ducados en el evento, a pesar de que estaba mandado que esos gastos no excediesen los $4.000^{25}$. Como parte de los festejos, los ingenios locales celebraron la entrada del nuevo virrey con composiciones poéticas (como la «Canción real panegírica» de Pedro de Oña) que, a pesar de no haber sido compiladas en una relación festiva, imaginamos circularon en la corte virreinal durante la ocasión ${ }^{26}$.

La «Canción real panegírica» de Oña muestra una cuidada inventio: el poema invoca a los montes de Lima que - personificados y en representación metafórica de los súbditos del virreinato - son llamados a sentir y a manifestar alivio y alegría, así como gratitud y sumisión, por la llegada del nuevo virrey, Juan de Mendoza y Luna, marqués de Montesclaros. Los ríos del virreinato, y en especial el Rímac, en cuyas aguas se espejean las cumbres de los montes limeños, también son apelados a manifestar tales afectos, mientras las aguas del Guadalquivir y de la laguna de México -igualmente personificadas - dan testimonio de las anteriores acciones de Montesclaros como adelantado en Sevilla y virrey en la Nueva España. Si la naturaleza es personificada, el virrey es inversamente metaforizado como monte, luna y otras variantes agudas por asociación con sus apellidos. Así, el poema afirma que el marqués (un «monte claro») viene a reemplazar a los montes de Lima en la sustentación del cielo antártico, labor que ahora descansa en los hombros del nuevo virrey.

Esta inventio recupera la tradición literaria de la invocación a la naturaleza 27 pero también implica, en su contexto específico, una poetización alegórica de la

24. Latasa, 2005, p. 61

25. San Lorenzo, 2.VIII.1614, AGI, Lima 582, Lib. 16, f. 124, citado por Latasa, 1997, p. 6.

26. Alejandra Osorio describió las entradas de los virreyes a Perú de la siguiente manera: «Cuando un virrey llegaba al Perú por El Callao y su navío era avistado desde la costa, la artillería del puerto hacía un saludo con armas de fuego y el barco del virrey lo respondía. Cuando desembarcaba recibía un nuevo saludo, al tiempo que los escuadrones de infantería y caballería ondeaban sus banderas. Luego lo recibían y saludaban en la playa la Audiencia, el cabildo de Lima y el capítulo eclesiástico de la catedral. Caminaban juntos hasta la iglesia del puerto, donde se oficiaba un te deum laudamus, un antiguo himno de alabanza que comenzaba diciendo "Te alabamos, señor" y que se utilizaba como expresión de agradecimiento en ocasiones especiales. Luego el virrey era conducido hacia la casa preparada para alojarlo, donde la ciudad ofrecía un banquete en su honor y llegaban a saludarlo personalidades importantes de la sociedad limeña, así como funcionarios locales y coloniales. La noche antes de su entrada, el virrey era entretenido en El Callao con juegos cortesanos, fuegos artificiales y música. La ruta y estructura de la entrada la decidía el nuevo virrey en consulta con las autoridades políticas y civiles de Lima», 2006, p. 768. 27. Tradición resumida por Curtius, quien menciona las oraciones y juramentos que invocan en la llíada no solo a los dioses sino también a la tierra, el cielo y los ríos; frecuente asimismo en la poesía latina, como por ejemplo en Estacio, el tópico se traspasa a la poesía cristiana, favorecido por los antecedentes bíblicos de las perturbaciones de la naturaleza frente a la muerte de Cristo o de la participación de la naturaleza en la alegría, como en el salmo XCVI, «Alégrense los cielos y gócese la tierra: brame la mar y su plenitud; regocíjese el campo y todo lo que en él está: entonces todos los árboles del bosque rebosarán 
idea de cuerpo político, fundamental en las concepciones teológico-políticas neoescolásticas ${ }^{28}$. Cuando murió María Luisa de Orleans, por ejemplo, la erupción del Etna fue interpretada como manifestación del luto de sus vasallos italianos ya «que el dolor de la cabeza todo el cuerpo le acompaña», dijo fray Francisco de Montalbo ${ }^{29}$. En otras palabras, la muerte de la reina («cabeza» del cuerpo político, junto al rey) provocaba dolor en el resto del cuerpo, universalidad cifrada en la unión de la naturaleza. En los funerales de Felipe II cayó una fuerte lluvia sobre Zaragoza, lo que se interpretó en sentido similar: «¿No veis como acompañan con sus lágrimas a las nuestras, para que sea más grave y más universal el llanto?», dijo fray Diego Murillo en su sermón ${ }^{30}$. Así, el tópico antiguo se revestía con las connotaciones de manifestación de la Providencia divina, correlación entre macro y microcosmos, creación divina como libro en que ningún signo es gratuito, todo lo cual se hacía especialmente evidente en la figura del rey (o la reina, o el virrey, en el caso americano) en cuanto «intermediario o gozne esencial, mitad humano, mitad personaje sagrado», «entre Dios y el hombre y las esferas superiores e inferiores» 31 .

Ahora bien, la manifestación universal de la alegría por la recepción de un nuevo gobernante también es parte de la retórica del encomio, tal como indica Menandro el Rétor en sus tratados de retórica epidíctica (Peri Epideiktikon). En el segundo tratado (que citaré como Menandro II), uno de los discursos sistematizados es justamente el epibatérios, discurso de llegada dirigido a un gobernador que va a establecerse en una ciudad o que ha tenido una estancia fuera de la misma ${ }^{32}$. Menandro explica que en este tipo de discursos el proemio se ha de basar, desde el principio, en una alegría desbordante, «pues hay que dar la impresión de compartir el regocijo ya de las ciudades, porque reciben a un gobernador admirado y elogiado, ya del gobernador, porque llega en buena hora, ya congratularse el propio orador consigo mismo, porque tiene ante los ojos a una ciudad o a un gobernador que, desde hacía tiempo y fervientemente, se deseaba ver» ${ }^{33}$. Menandro recomienda decir al nuevo gobernador que llega «con buenos auspicios de parte del emperador, resplandeciente como un luminoso rayo de sol que se nos muestra desde arriba» 34 y, en lo posible, la misma ciudad debería hablar, personificada, tomando «forma de

de contento» (citado por Curtius, 1995, p. 140). De menor presencia en la poesía medieval, la invocación a la naturaleza y su participación en los afectos tendrá un enorme desarrollo en el Renacimiento, en especial en la poesía bucólica (ver Curtius, 1995, pp. 141-142).

28. Concepción corporativista del Estado como cuerpo místico de voluntades subordinadas al rey a través del pacto de sujeción, que reitera que las instituciones existentes son no solo legales, sino principalmente legítimas, porque son la expresión visible de la ley natural de la gracia innata. Más detalles sobre este concepto político y su aplicación en programas festivos americanos en Hansen, 2001.

29. En Noticias fúnebres, p. 22, citado por Varela, 1990, p. 102.

30. Sermón pronunciado en Zaragoza, 1599, citado por Varela, p. 102. Además de la lluvia, los ríos fueron una imagen central en los programas de exequias: los ríos que desembocan en el mar simbolizan la universalidad de la muerte, pero también son la expresión del llanto en una proporción cósmica. Para más detalles, ver Varela, 1990 y Azanza, 2011

31. Varela, 1990, p. 107.

32. Menandro, Dos tratados de retórica epidíctica, p. 162

33. Menandro, Dos tratados de retórica epidíctica, p. 162.

34. Menandro, Dos tratados de retórica epidíctica, pp. 162-163. 
mujer, como en el drama», exclamando «ioh, gobierno el más grande, y día felicísimo el de tu llegada! iAhora la luz del sol es más luminosa; ahora, como al salir de la oscuridad, parece que tenemos ante los ojos un resplandeciente día!»35.

Buena parte de la poesía encomiástica de la antigüedad tardía podría definirse como una aplicación de esta preceptiva retórica epidíctica. El alejandrino Claudio Claudiano es uno de estos poetas tardíos y seguramente sirvió de modelo a Pedro de Oña (antes que a Góngora en su «Panegírico al duque de Lerma»). En concreto, el primer poema publicado por Claudiano en latín, el Panegyricus dictus Probino et Olybrio consulibus (enero de 395), guarda un parecido notable con la «Canción real panegírica» de Oña. En el Panegyricus dictus Probino et Olybrio consulibus, se parte con una invocación al sol. Así como Oña pide, en la primera estancia de su canción, que los montes de Lima se huelguen y alegren por la llegada del nuevo virrey, en los primeros versos del Panegyricus, Claudiano pide al sol que muestre un día especialmente luminoso para festejar el consulado de los hermanos ${ }^{36}$. Luego, cuando refiere al regreso del emperador Teodosio a Roma, el Panegyricus dice que «tres veces resonaron las rocas y se estremeció el negro bosque, conscientes de su majestad» 37 , tal como Oña pedirá a los montes de Lima que choquen de placer («unos con otros de placer chocando, / corred a celebrar esta venida, / y vengan de avenida / a vuestro ejemplo los caudales ríos / con sesgo paso y apacible estruendo», vv. 67-71). La invitación a los ríos también procede de Claudiano: en el Panegyricus, Júpiter invita a todos los ríos a la mesa común, que todas las corrientes celebren el honroso día (vv. 248-258).

Además, como en Oña, también son los ríos los que dan cuenta de las acciones pasadas virtuosas: si en la canción, el Guadalquivir y la laguna mexicana hablan de las virtudes del virrey, en el Panegyricus, la liberalidad de Probo, padre de los hermanos cónsules, es comparada a la fertilidad de los ríos iberos, los tesoros del Tajo, las valiosas riberas del Hermo, las rutilantes arenas del Pactolo ${ }^{38}$. Y si Clau-

35. Menandro, Dos tratados de retórica epidíctica, p. 167.

36. Sol, qui flammigeris mundum conplexus habenis

volvis inexhausto redeuntia saecula motu,

sparge diem meliore coma, crinemque repexi

blandius elato surgant temone iugales

efflantes roseum frenis spumantibus ignis

iam nova germanis vestigia torqueat annus

consulibus, laetique petant exordia menses (vv. 1-7).

En la traducción de Miguel Castillo Bejarano: «Oh Sol, que, abrazando el mundo con tus flamígeras riendas, haces girar en infatigable movimiento a los siglos en su sucesión, esparce la luz con rayos más esplendorosos y que tus caballos, peinadas sus crines, se eleven con el carro alzado con más cariño, exhalando por sus espumantes frenos un fuego rosado. Que el año encamine ya sus primeros pasos al consulado de los dos hermanos y los meses traten de alcanzar alegres su nacimiento», Claudiano, Poemas, p. 121

37. Ut stetit ante ducem discussas Roma per auras,

conscia ter sonuit rupes et inhorruit atrum

maiestate nemus (vv. 124-126). Claudiano, Poemas, p. 128.

38. vv. 48-54: «Aquella mano pródiga superaba a los ríos iberos distribuyendo áureos regalos, cuanto oro contempla admirado en la tierra removida el minero que excava afanosamente en las colinas, cuantos 
diano refiere a la riqueza de estos ríos, también Oña invoca las del Perú que, si bien se «cegaron», dejando sediento el suelo tras la muerte del anterior virrey, ahora con Montesclaros volverán a ofrecer sus arenas de oro («las urnas sacras de cristal vertiendo / y dando por ofrenda (entre sombríos / ramos de verdes cañas) / arenas de oro, no puras entrañas», vv. 72-75).

Por otro lado, los tópicos tratados por cada una de las estancias de la canción de Oña siguen la preceptiva del epibatérios aun más directamente que el mismo Panegyricus de Claudiano. En su formación como licenciado, Pedro de Oña pudo familiarizarse con esa preceptiva retórica transmitida tanto en tratados epidícticos (como los de Menandro) como en los progymnásmata. Sintetizo las coincidencias en el siguiente cuadro:

\begin{tabular}{|c|c|}
\hline $\begin{array}{c}\text { Epibatérios o discurso de llegada } \\
\text { según Menandro II }\end{array}$ & $\begin{array}{l}\text { Canción real panegírica de Pedro de } \\
\text { Oña como epibatérios poético }\end{array}$ \\
\hline $\begin{array}{l}\text { Proemio: alegría desbordante de la } \\
\text { ciudad que recibe al gobernador. }\end{array}$ & $\begin{array}{l}\text { Estancia 1: proemio: alegría desbordante de } \\
\text { la ciudad (por sinécdoque, los montes de } \\
\text { Lima). }\end{array}$ \\
\hline $\begin{array}{l}\text { Tratamiento de los súbditos: si han recibi- } \\
\text { do mal trato por el gobernador anterior, se } \\
\text { hará una descripción detallada de las difi- } \\
\text { cultades aunque sin injuriar al gobernador } \\
\text { saliente. Luego, se añade que, tras las difi- } \\
\text { cultades, el nuevo gobernador disipó la os- } \\
\text { curidad como un sol. }\end{array}$ & $\begin{array}{l}\text { Estancia 6: las aguas del Perú se cegaron } \\
\text { con la muerte del virrey anterior. } \\
\text { Estancia 7: la muerte del virrey anterior } \\
\text { es representada como una noche oscura; } \\
\text { Montesclaros viste de nueva luz el mundo } \\
\text { nuevo. }\end{array}$ \\
\hline $\begin{array}{l}\text { Acciones anteriores del gobernador (si las } \\
\text { hay). }\end{array}$ & $\begin{array}{l}\text { Estancia 8: el virrey fue asistente en Sevilla } \\
\text { (elogio). } \\
\text { Estancia 9: contuvo la inundación de Mé- } \\
\text { xico cuando fue virrey de la Nueva España } \\
\text { (elogio). }\end{array}$ \\
\hline Ciudad natal o nación. & --- \\
\hline Acciones de su familia. & $\begin{array}{l}\text { Estancia 4: referencia a su insigne tío, Mar- } \\
\text { tín de Padilla, adelantado de Castilla. } \\
\end{array}$ \\
\hline $\begin{array}{l}\text { Virtudes del nuevo gobernador (justicia, va- } \\
\text { lor, sabiduría, otras). }\end{array}$ & $\begin{array}{l}\text { Estancia 4: valor, émulo del insigne tío. } \\
\text { Estancia 5: fuerte cerviz y hombros valien- } \\
\text { tes. } \\
\begin{array}{l}\text { Commiato: la canción debe parar por no } \\
\text { ofender la modestia del virrey. }\end{array}\end{array}$ \\
\hline
\end{tabular}

tesoros arrastran las aguas del Tajo, que se filtran con sus filones en bruto; cantidad de metal comparable a aquella con la que resplandecen las valiosas riberas del Hermo y equivalente a todas las rutilantes arenas que el rico Pactolo esparce espumante por los campos de Lidia», Claudiano, Poemas, p. 124. 


\begin{tabular}{|l|l|}
\hline \multicolumn{1}{|c|}{$\begin{array}{c}\text { Epibatérios o discurso de llegada } \\
\text { según Menandro II }\end{array}$} & $\begin{array}{l}\text { Canción real panegírica de Pedro de } \\
\text { Oña como epibatérios poético }\end{array}$ \\
\hline $\begin{array}{l}\text { Conjetura y deducción de cómo será el } \\
\text { próximo gobierno (en concordancia con las } \\
\text { virtudes). }\end{array}$ & $\begin{array}{l}\text { Estancia 2: se anuncia seguridad en la tierra } \\
\text { durante el gobierno del próximo virrey. }\end{array}$ \\
& $\begin{array}{l}\text { Estancia 3: se anuncia seguridad en los ma- } \\
\text { res. }\end{array}$ \\
\hline $\begin{array}{l}\text { La ciudad habla personificada, manifestan- } \\
\text { do la alegría por el nuevo gobierno. }\end{array}$ & $\begin{array}{l}\text { Estancia 10: Habla el río (sinécdoque de } \\
\text { Lima): «iOh, Náyades!, diciendo, veis llegado } \\
\text { / el cuando a las coyundas españolas...» }\end{array}$ \\
\hline
\end{tabular}

Como puede verse, la «Canción real panegírica» contiene, aunque con distinto orden, prácticamente todos los tópicos previstos para el discurso de llegada. El tratamiento elocutivo de dichos tópicos dialoga con la inventio del Panegyricus de Claudiano, pero se funda, principalmente, en una variación aguda que se ajusta por completo a las preferencias cortesanas de la época, como mostraré en las páginas que siguen.

\section{UN CLARO MONTE PARA EL CIELO ANTÁRTICO: CORTESANÍA Y AGUDEZA}

Como quedó señalado, los tópicos de la retórica epidíctica (específicamente, los del epibatérios o discurso de llegada) fueron fundamentales para la inventio de la «Canción real panegírica». Dicho modelo retórico orientó al poeta en la definición de las ideas expuestas en el poema. Sin embargo, tales ideas adquirieron su auténtico perfil al ajustarse a las estrategias poéticas que, durante los siglos XVI y XVII, caracterizaron a la poesía cortesana, en especial, el empleo de tropos (como la alegoría) con el fin de oscurecer o alejar el significado y a la vez insinuar amplios sentidos por medio de un lenguaje indirecto, similar a la práctica política de la disimulación ${ }^{39}$.

En la «Canción real panegírica», toda la elocutio deriva de una figura central: el juego metafórico con el nombre del nuevo virrey. La primera estancia presenta la metáfora principal, con su continuación alegórica: el virrey es un monte claro en el que descansará el cielo antártico, en reemplazo de los «soberbios montes de la regia Lima»

$$
\begin{aligned}
& \text { Soberbios montes de la regia Lima, } \\
& \text { que en el puro cristal de vuestro río, } \\
& \text { de las nevadas cumbres despeñado, } \\
& \text { arrogantes miráis la enhiesta cima } \\
& \text { tan esenta al rigor del calmo estío } \\
& \text { como a las iras del hivierno helado, } \\
& \text { si en los robustos hombros sustentado } \\
& \text { habéis el cielo antártico hasta agora, }
\end{aligned}
$$

39. Remito a las ideas de Javitch, 1978, tal como sinteticé páginas atrás. 


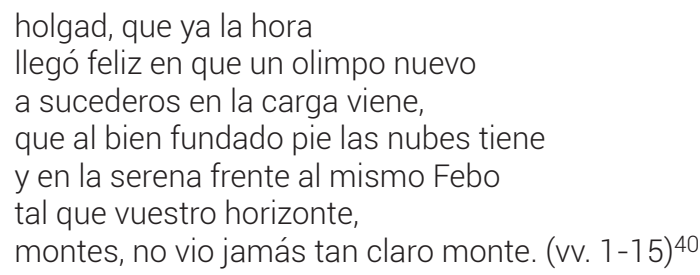

Desde antiguo, el nombre es uno de los atributos de persona que, tanto en el discurso jurídico como en el epidíctico, amerita un tratamiento específico ${ }^{41}$. Aquí, sin embargo, este atributo se convierte en locus aglutinador de todo el poema: la elocución de cada uno de los tópicos del epibatérios deriva de metáforas y símiles motivados por esta metáfora inicial del virrey como «monte claro». Oña procede estableciendo conexiones por semejanza a partir del campo semántico sugerido por el nombre del virrey (monte, luna, claridad, luz, etc.). Su metodología es similar a la que, décadas después, sistematizará Baltasar Gracián en Agudeza y arte de ingenio (1648): «caréase el sujeto, no ya con sus adyacentes propios, sino con un término extraño, como imagen que le exprime su ser o le representa sus propiedades, efectos, causas, contingencias y demás adjuntos, no todos, sino algunos, o los más principales» ${ }^{42}$. En la «Canción real panegírica», el virrey es «careado» con un término extraño («monte» o «luna») para generar símiles que den cuenta de sus virtudes, acciones, etc.; pero ese término extraño es - a la vez- propio, ya que contenido en su nombre. El mismo Gracián refiere también a las agudezas derivadas del nombre del sujeto, como en la redondilla:

$$
\begin{aligned}
& \text { En un medio está mi amor, } \\
& \text { y-sabe-él } \\
& \text { que si en medio está el sabor, } \\
& \text { en los extremos la I-el. }
\end{aligned}
$$

De la que comenta: «Fúndase en el nombre de Isabel, que, dividido, la primera sílaba, que es I, y la última el, dicen lel, y en medio queda el sabe» ${ }^{43}$. Isabel aparece, aquí, adherida a un «término extraño», la hiel, término que estaba escondido, sin embargo, en su propio nombre, exprimiendo el ser dulce y amargo de la amante. Comenta Gracián que la intención del poeta era dejar en silencio el nombre de su $a_{m o r}{ }^{44}$. Ese silencio del nombre revela, no obstante, un escondido secreto que ilumina un aspecto fundamental de la mujer. Del mismo modo, en el caso del marqués de Montesclaros, la imagen del virrey como un monte da lugar a varias derivacio-

40. Oña, «Canción real panegírica», en Temblor de Lima, 1609, fol. 18. Modernizo las grafías sin valor fonemático, como en mi edición. Por razones de espacio, no podré tratar aquí el referente mitológico de Hércules y Atlas implícito en toda la canción y presente ya en esta primera estancia. Remito al lector interesado al estudio preliminar de mi edición en prensa.

41. Así se indica ya en De inventione de Cicerón: nomen es el primer atributo de persona e indica «aquello que se da a cada persona y sirve para designarla con una apelación propia y definida», p. 132.

42. Gracián, Agudeza y arte de ingenio, p. 491.

43. Gracián, Agudeza y arte de ingenio, p. 438.

44. Gracián, Agudeza y arte de ingenio, p. 438. 
nes agudas que sustituyen totalmente el empleo del nombre, nunca mencionado en el poema sino a través de metáforas, tal como resumo en el siguiente cuadro:

\begin{tabular}{|c|c|c|}
\hline Estancias & $\begin{array}{c}\text { Metáforas que nombran al } \\
\text { virrey }\end{array}$ & Alegoría \\
\hline Estancia 1 & $\begin{array}{l}\text { olimpo nuevo } \\
\text { claro monte }\end{array}$ & $\begin{array}{l}\text { Los montes de Lima, que } \\
\text { han sustentado hasta aho- } \\
\text { ra el cielo antártico, pueden } \\
\text { descansar, pues ha llegado } \\
\text { un claro monte que viene a } \\
\text { sucederlos en la carga. }\end{array}$ \\
\hline Estancia 2 & alto monte que señorea & $\begin{array}{l}\text { Al abrigo y a la sombra de } \\
\text { este monte claro, y en su } \\
\text { fértil y espaciosa falda, vol- } \\
\text { verá una edad de oro, la que } \\
\text { ni siquiera un cerro de pla- } \\
\text { ta del Perú pudo traer an- } \\
\text { tes (tanto era el hierro de la } \\
\text { edad previa). }\end{array}$ \\
\hline Estancia 3 & $\begin{array}{l}\text { eminente faro } \\
\text { monte claro } \\
\text { sol en descubierto día } \\
\text { monte de la luna (visible en } \\
\text { la noche bruna) }\end{array}$ & $\begin{array}{l}\text { Las embarcaciones peque- } \\
\text { ñas y grandes pueden na- } \\
\text { vegar tranquilas, sin temor a } \\
\text { corsarios, pues el eminente } \\
\text { faro del monte claro envía } \\
\text { luz igual a todas partes. }\end{array}$ \\
\hline Estancia 4 & luna & $\begin{array}{l}\text { El virrey es una luna que } \\
\text { resplandece llena y limpia } \\
\text { iluminada por los rayos de } \\
\text { sol mendocino (de los Men- } \\
\text { doza). El virrey ha devuelto } \\
\text { la esperanza a su linaje, en } \\
\text { cuanto émulo ilustre de su } \\
\text { insigne tío, don Martín Padi- } \\
\text { lla (la gloria de Padilla). }\end{array}$ \\
\hline
\end{tabular}




\begin{tabular}{|c|c|c|}
\hline Estancias & $\begin{array}{c}\text { Metáforas que nombran al } \\
\text { virrey }\end{array}$ & Alegoría \\
\hline Estancia 5 & nueva soberana cumbre & $\begin{array}{l}\text { Los montes de Lima de- } \\
\text { ben inclinar, humildes, sus } \\
\text { altivas frentes ante la nue- } \\
\text { va soberana cumbre, y en } \\
\text { su fuerte cerviz y hombros } \\
\text { valientes deben apoyar su } \\
\text { pesadumbre, chocando de } \\
\text { placer por la venida del nue- } \\
\text { vo virrey. Los ríos deben se- } \\
\text { guir el ejemplo de los mon- } \\
\text { tes y entregar como ofrenda } \\
\text { arenas de oro vertidas de las } \\
\text { urnas sacras de su cristal. }\end{array}$ \\
\hline Estancia 6 & $\begin{array}{l}\text { otro monte que el mismo } \\
\text { cielo envía }\end{array}$ & $\begin{array}{l}\text { Con la muerte del virrey an- } \\
\text { terior, el Conde de Monte- } \\
\text { rrey, las aguas del Perú se } \\
\text { secaron, la tierra se quejó; } \\
\text { ahora que el antiguo virrey } \\
\text { pisa las estrellas, el mismo } \\
\text { cielo envía otro monte; de } \\
\text { monte a monte viene el bien } \\
\text { al reino. }\end{array}$ \\
\hline Estancia 7 & $\begin{array}{l}\text { nueva luz que viste el nuevo } \\
\text { mundo } \\
\text { monte en medio }\end{array}$ & $\begin{array}{l}\text { Tras la noche oscura de } \\
\text { la ausencia de Monterrey, } \\
\text { Montesclaros alegra el día } \\
\text { vistiendo de nueva luz el } \\
\text { nuevo mundo; esa luz des- } \\
\text { vía al malhechor que esta- } \\
\text { ba en la tiniebla, y la noble } \\
\text { matrona no peligra su honor } \\
\text { porque el monte en medio le } \\
\text { asegura la casa y el reme- } \\
\text { dio. }\end{array}$ \\
\hline
\end{tabular}




\begin{tabular}{|c|c|c|}
\hline Estancias & $\begin{array}{l}\text { Metáforas que nombran al } \\
\text { virrey }\end{array}$ & Alegoría \\
\hline Estancia 8 & sublime celsitud & $\begin{array}{l}\text { El anciano Betis (antiguo } \\
\text { nombre del Guadalquivir, } \\
\text { alusión tanto al río como al } \\
\text { rey Betis) da testimonio de } \\
\text { la seguridad que provee este } \\
\text { monte claro. El Betis sirvió } \\
\text { al joven marqués de claro } \\
\text { espejo durante su periodo } \\
\text { como asistente de Sevilla, } \\
\text { pero quizás también el an- } \\
\text { ciano tomó consejo del jo- } \\
\text { ven, para no turbar sus cla- } \\
\text { ras linfas. Lo jura también } \\
\text { el mexicano lago (alusión a } \\
\text { sus inundaciones, tema de } \\
\text { la estancia siguiente). }\end{array}$ \\
\hline Estancia 9 & gallardo brío & $\begin{array}{l}\text { Si el Guadalquivir y la laguna } \\
\text { de México trocasen el mur- } \\
\text { murio blando de sus aguas } \\
\text { por hábiles lenguas, podrían } \\
\text { decir del fracaso y reparo } \\
\text { milagroso cuando, a punto } \\
\text { de lanzarse, el virrey (gallar- } \\
\text { do brío) retrujo del agua au- } \\
\text { daz el abundante flujo. }\end{array}$ \\
\hline Estancia 10 & luna & $\begin{array}{l}\text { El mar detuvo al virrey sobre } \\
\text { sus ondas, con importunas } \\
\text { calmas y nubes, como ven- } \\
\text { ganza del agravio recibido } \\
\text { por sus hijos (el río Guadal- } \\
\text { quiviry la laguna mexicana), } \\
\text { pero el cielo santo acudió } \\
\text { y al fin se dejó ver la luna. } \\
\text { Lima, al gran concurso de } \\
\text { almas que vinieron a verla (a } \\
\text { la luna), olvidó su curso. }\end{array}$ \\
\hline
\end{tabular}




\begin{tabular}{|c|c|c|}
\hline Estancias & $\begin{array}{c}\text { Metáforas que nombran al } \\
\text { virrey }\end{array}$ & Alegoría \\
\hline Estancia 11 & montes claros & $\begin{array}{l}\text { El río, que había olvidado su } \\
\text { curso, en furor divino arre- } \\
\text { batado, alza el cuello entre } \\
\text { espumantes olas y celebra } \\
\text { el momento en que las co- } \\
\text { yundas españolas somete- } \\
\text { rán la cerril melena de Arau- } \\
\text { co, y la ciudad que suena de } \\
\text { su nombre (Rímac-Lima) } \\
\text { tendrá paz, como Roma } \\
\text { cuando reinaba Numa Pom- } \\
\text { pilio. Al reino se le pide prue- } \\
\text { ba de noble gratitud y a los } \\
\text { montes que oyen la nueva } \\
\text { que cambien su color de } \\
\text { nieblas pardas, de montes } \\
\text { oscuros en montes claros. }\end{array}$ \\
\hline Commiato & $\begin{array}{l}\text { Argos vigilante en merecer } \\
\text { alabanzas }\end{array}$ & $\begin{array}{l}\text { Se pide a la canción que } \\
\text { pare, pues, aunque el furor } \\
\text { labra ambos ijares, del freno } \\
\text { tira el no saber con qué ojos } \\
\text { mira estas alabanzas el que } \\
\text { no abre sus ojos a ellas (el } \\
\text { virrey). Este, sin embargo, } \\
\text { es como un Argos vigilante } \\
\text { (vale decir, tiene cien ojos) } \\
\text { para merecerlas. }\end{array}$ \\
\hline
\end{tabular}

Como se puede observar, las metáforas empleadas para nombrar al virrey se inscriben en dos campos semánticos fundamentales: el de la luz o la claridad (monte claro que en la frente tiene al mismo Febo, eminente faro, etc.) y el de la altura (soberana cumbre, alto monte que señorea, etc.). Todas connotan la majestad del virrey, especialmente las metáforas del sol y la luna (fuentes de la claridad) pues son imágenes tradicionalmente empleadas en la emblemática para representar alegóricamente a los soberanos. Al evitar el nombre del virrey y emplear solo las metáforas señaladas, el poeta enaltece la majestad de Juan de Mendoza y Luna manteniendo, no obstante, el decoro necesario tanto para distinguir la alabanza de la vil adulación como para sugerir la grandeza del marqués sin herir su (esperada) modestia. Si el propio nombre del marqués revela, a través de la sutileza de las conexiones agudas, su condición elevada, esta no es fruto de la adulación panegírica sino evidencia cifrada en su nombre, el que, por lo mismo, se omite. El decoro es, de hecho, el tema del commiato que pone fin a la canción:

Parad, canción, aunque el furor os labre ambos ijares, pues del freno os tira 
el no saber los ojos con que os mira quien a sus alabanzas no los abre, tan sin ellos en ellas cuan Argos vigilante en merecellas (vv. 166-171)

En términos de Gracián, hay aquí agudeza ya no por semejanza o proporción sino por extrema desproporción o disonancia ${ }^{45}$. El poeta detiene la canción por no saber con qué ojos mira estas alabanzas el que no los abre para verlas (es decir, el modesto virrey). La improporción es triple: tan cerrados tiene el marqués los ojos para ver sus propios méritos como abiertos para hacer lo digno de alabanza (Argos vigilante), y tan sin ellos (ojos) está en ellas (alabanzas) como mira la canción (la lee) sin que el poeta sepa con qué ojos lo hace (con qué reacción).

Toda esta cuidada elocutio busca cautivar al nuevo virrey y al mismo tiempo sugerir, a través de los sutiles halagos del encomio, un ideal de próximo gobierno. Como quedó señalado páginas atrás, la imagen del virreinato entero - súbditos y naturaleza - manifestando alegría y alivio, gratitud y sumisión, representa el cuerpo místico de voluntades subordinadas al rey a través del pacto de sujeción, el que se renueva con la llegada de su alter ego a Indias. Esa renovación también recordaba al virrey que su poder se asentaba en la legitimidad de su gobierno, es decir, en la realización de acciones encaminadas al bien común de ese mismo cuerpo. En concreto, la «Canción real panegírica» sugería al virrey que se preocupara por la seguridad del virreinato, tanto de la tierra como del mar (amenazado por piratas), que por fin sometiera «la cerril melena» de Arauco a las «coyundas españolas» y que asegurara la paz en el reino, como un Numa Pompilio en la antigua Roma. Este último aparecía, así, como un espejo en el que debería mirarse el virrey entrante. Vale la pena recordar lo que de Numa Pompilio dijera Plutarco en sus Vidas paralelas: desterró «de su casa todo lujo y superfluidad, manifestándose juez y consejero irreprensible al propio y al extraño, y empleando en cuanto a sí mismo el tiempo que le quedaba libre, no en placeres o comodidades, sino en el culto de los dioses, y en el conocimiento de su naturaleza y de su poder ${ }^{46}$. En el lenguaje de la disimulación encomiástica, basta un ejemplo como este para sugerir ideales que el marqués (como la mayor parte de la nobleza en la época de la decadencia) estaba lejos de encarnar ${ }^{47}$.

\section{CONCLUSIONES}

A comienzos del siglo XVII, el poeta criollo Pedro de Oña compuso una canción panegírica para recibir a Juan de Mendoza y Luna como nuevo virrey del Perú.

45. «La más agradable y artificiosa es cuando dicen entre sí contrariedad los extremos de la desproporción» y «cuando es mayor la repugnancia, hace más conceptuosa la improporción», Gracián, Agudeza y arte de ingenio, pp. 464-465.

46. Plutarco, «Licurgo y Numa Pompilio», en Vidas paralelas.

47. Más detalles sobre la cuestionable actuación política de Montesclaros como ejemplo de la nobleza española en decadencia a comienzos del siglo XVII, en Cabrillana, 1969. Una mirada más detenida del gobierno peruano de Montesclaros en Latasa, 1997. 
Para ello, se valió de la tradición retórica epidíctica, en particular de la preceptiva del epibatérios sistematizada por Menandro en su segundo tratado. La canción de Oña recupera prácticamente todos los tópicos previstos para este tipo de discurso. En la canción, dichos tópicos se integran a una inventio donde la invocación a la naturaleza y su participación en el regocijo y sumisión ante la llegada del virrey es central. En ese aspecto, la canción de Oña emula el Panegyricus dictus Probino et Olybrio consulibus (395) de Claudiano, quien también había seguido la preceptiva epidíctica sistematizada en época imperial.

Como es de esperar en la doctrina de la imitatio, Pedro de Oña no imitó servilmente estos modelos sino que los adaptó a su contexto con gran ingenio. En un plano más general, esa adaptación consistió en el empleo del lenguaje de la cortesanía, el que llevó a oscurecer el sentido del poema a través de la alegoría aguda, para transmitir consejos políticos bajo el atractivo de la alabanza. En un plano más específico, los modelos se ajustaron también a la persona del virrey, el marqués de Montesclaros, y al espacio americano, el virreinato del Perú. Esta última acomodación es de sumo interés pues, junto a la alabanza del virrey, la canción sugiere una sutil reivindicación del entorno natural peruano (los soberbios montes de la regia Lima, las arenas de oro de sus ríos, el cerro de plata, etc.) y de sus poetas, los ingenios que le daban a ese «cielo antártico» no los hombros para sustentarlo, pero sí sus «lenguas expedidas». Esa misma reivindicación está presente en toda la obra de Oña al marqués.

En ese aspecto, la canción de Pedro de Oña participaba, en realidad, de un esfuerzo colectivo, común a los poetas vinculados a la Academia Antártica. En su calidad de poema de recepción al virrey, la canción de Oña anunciara, de hecho, metáforas e ideas que seguirían presentes en algunas composiciones poéticas posteriores, como el soneto laudatorio dirigido al marqués por el doctor Alonso de Huerta, en su Arte de la lengua quechua general de los Indios de este Reino del Perú (Lima, 1616), donde el marqués aparece como luna que viene a dar luz al Nuevo Mundo, o las octavas 6 y 7 del canto I de Armas antárticas de Juan de Miramontes Zuázola, donde se señala que el marqués sustenta el orbe antártico en sus hombros, y principalmente en las octavas 1210 a 1213 del canto XIII, donde los pronósticos favorables de la canción de Oña aparecen como realidad, a pocos años del gobierno del marqués:

Cualquier constelación, astro, planeta ya de aspecto benévolo se acata, ya la abundante tierra en su secreta vena cría esmeraldas, oro y plata; ya usa el caballero la jineta, ya el codicioso mercader contrata, ya enriquecen el campo los haberes del semicabra Pan, Minerva y Ceres.

Ya el armígero bárbaro araucano en el valiente pecho miedo imprime, ya el pirata cismático albïano 


\author{
el atrevido navegar reprime \\ viendo que don Juan la hercúlea mano \\ la fuerte y victoriosa espada esgrime, \\ siendo ya del Perú bastante amparo \\ la refulgente luz del Monte Claro ${ }^{48}$.
}

\title{
BIBLIOGRAFÍA
}

Anónimo, Epístola de Amarilis a Belardo, ed. Martina Vinatea, Madrid/Universidad de Navarra, Iberoamericana/Vervuert, 2009.

Arellano, Ignacio, «Algunos aspectos de la relación literatura-nobleza en el Barroco», Il confronto letterario, 30, 1998, pp. 331-353.

Arellano, Ignacio y Victoriano Roncero, «Introducción», en Quevedo, Francisco de, La Musa Clío del Parnaso español, Pamplona, Ediciones Universidad de Navarra, 2001, pp. 5-38.

Azanza, José Javier, «Oración fúnebre, emblemática y jeroglíficos en las exequias reales: palabra e imagen al servicio de la exaltación regia», en Emblemática trascendente, ed. Rafael Zafra y José Javier Azanza, Pamplona, Sociedad Española de Emblemática/Universidad de Navarra, 2011, pp. 174-194.

Blanco, Mercedes, «El panegírico al duque de Lerma como poema heroico», en El duque de Lerma: poder y literatura, ed. Juan Matas Caballero, José María Micó Juan y Jesús Ponce Cárdenas, Madrid, Centro de Estudios Europa Hispánica, 2011. pp. 11-56

Buxó, José Pascual (ed.), Permanencia y destino de la literatura novohispana. Historia y crítica, México, Universidad Nacional Autónoma de México, 2006.

Buxó, José Pascual (ed.), Reflexión y espectáculo en América colonial, México, UNAM, 2007.

Carneiro, Sarissa, «Temblor de Lima (1609) de Pedro de Oña: poética del desastre y encomio virreinal», Anales de Literatura Chilena, 17, 2016, pp. 133-153.

Cabrillana, Nicolás, «Un noble en decadencia: el virrey Marqués de Montesclaros (1571-1628)», Revista de Indias, XXIX, n 115, 1969, pp. 107-150.

Claudiano, Poemas, tomo I, ed. Miguel Castillo Bejarano, Madrid, Gredos, 1993.

Chastel, André, «Le baroque et la mort», En Retorica e Barocco. Atti del III Congresso Internazionale di Studi Umanistici, ed. Enrico Castelli, Roma, Fratelli Bocca Editori, 1955, pp. 33-53.

Cicerón, La invención retórica, Madrid, Gredos, 1997.

Curtius, Ernst Robert, Literatura europea y Edad Media latina, vol. 1, trad. Margit Frenk y Antonio Alatorre, México, Fondo de Cultura Económica, 1995. 
Javitch, Daniel, Poetry and courtliness in Renaissance England, Princeton, Princeton University Press, 1978.

Farré, Judith, Dramaturgia y espectáculo del elogio. Loas completas de Agustín de Salazar y Torres, vol I. Estudio, Kassel, Edition Reichenberger, 2003.

Farré, Judith, «Teatro y poder en el México virreinal: la dramática panegírica en torno a la figura del virrey», en Permanencia y destino de la literatura novohispana. Historia y crítica, ed. José Pascual Buxó, México, Universidad Nacional Autónoma de México, 2006.

Farré, Judith (ed.), Teatro y poder en la época de Carlos II. Fiestas en torno a los reyes y virreyes, Madrid/Frankfurt, Iberoamericana/Vervuert, 2007.

Farré, Judith (ed.), Espacio y tiempo de fiesta en Nueva España (1665-1760), Madrid/Frakfurt, Iberoamericana/Vervuert, 2013.

Fumaroli, Marc, «Retórica, política y sociedad: del ciceronianismo al clasicismo francés», en La elocuencia en el Renacimiento. Estudios sobre la teoría y la práctica de la retórica renacentista, ed. James Murphy, Madrid, Visor, 1999, pp.301-324.

Gracián, Baltasar, Agudeza y arte de ingenio, en Obras completas, ed. Santos Alonso, Madrid, Cátedra, 2011, pp. 431-808.

Hansen, João Adolfo, «A categoria representação nas festas coloniais dos séculos XVII e XVIII», en Festa. Cultura e Sociabilidade na América Portuguesa, vol. 2, ed. István Jancsó e Iris Kantor, São Paulo, EDUSP/Hucitec, 2001, pp. 735-755.

Latasa, Pilar, Administración virreinal en el Perú: gobierno del marqués de Montesclaros (1607-1615), Madrid, Editorial Centro de Estudios Ramón Areces, 1997.

Latasa, Pilar, «Transformaciones de una élite: el nuevo modelo de 'nobleza de letras' en el Perú (1590-1621)», en Elites urbanas en Hispanoamérica (De la conquista a la independencia), coord. Luis Navarro García, Sevilla, Secretariado de Publicaciones de la Universidad de Sevilla, 2005, pp. 413-433.

Menandro el Rétor, Dos tratados de retórica epidíctica, introducción de Fernando Gascó, traducción y notas de Manuel García García y Joaquín Gutiérrez Calderón, Madrid, Gredos, 1996.

Mínguez, Víctor y otros, La fiesta barroca: los Virreinatos americanos (1560-1808). Triunfos barrocos, vol. II, Castelló de la Plana, Publicaciones de la Universitat Jaume I, Las Palmas, Universidad de las Palmas de Gran Canaria, 2012.

Miramontes, Juan de, Armas antárticas, ed. Paul Firbas, Lima, Pontificia Universidad Católica del Perú, 2006.

Miró Quesada, Aurelio, El primer Virrey-poeta en América (Don Juan de Mendoza y Luna, Marqués de Montesclaros), Madrid, Gredos, 1962. 
Oña, Pedro de, Temblor de Lima, año de 1609, gobernando el marqués de Montes Claros, virrey excelentísimo, y una canción real panegírica, en la venida de su excelencia a estos reinos, Lima, Francisco del Canto, 1609.

Oña, Pedro de, «Canción real al Excelentísimo señor don Juan de Mendoza y Luna, marqués de Montes Claros, virrey del Pirú», 1612, en León, Martín de. Relación de las exequias que el excelentísimo señor don Juan de Mendoza y Luna, marqués de Montesclaros, virrey del Pirú, hizo en la muerte de la Reina nuestra señora doña Margarita (1612), Lima, Pedro de Merchán y Calderón, 1613.

Osorio, Alejandra, Inventing Lima. The Making of an Early Modern Colonial Capital, ca. 1540-1640, Tesis doctoral, New York, State University of New York at Stony Brook, 2001.

Osorio, Alejandra, «La entrada del virrey y el ejercicio de poder en la Lima del siglo XVII», Historia Mexicana, LV, 3, 2006, pp. 767-831.

Pernot, Laurent, La Rhéthorique de l'éloge dans le monde gréco-romain, tome I, Histoire et technique, tome II, Les valeurs, Paris, Institut d'Études Agustiniennes, 1993.

Ponce, Jesús, «El Panegírico al duque de Lerma. Trascendencia de un modelo gongorino (1617-1705)», Mélanges de la Casa de Velázquez. Nouvelle série, 42.1, 2012, pp. 71-93.

Quevedo, Francisco de, El Parnaso español, monte en dos cumbres dividido, con las nueve musas castellanas, ed. González de Salas, Madrid, Diego Díaz de la Carrera, 1648.

La Musa Clío del Parnaso español, ed. Ignacio Arellano y Victoriano Roncero, Pamplona, Ediciones Universidad de Navarra, 2001.

Rey, Alfonso, «Estudio», en Quevedo, Francisco de, Poesía moral (Polimnia), ed. Alfonso Rey, Madrid, Támesis, 1992.

Roncero, Victoriano, «Poesía histórica y política de Quevedo», Rivista di Filologia e Letterature Ispaniche, 3, 2000, pp. 249-262.

Varela, Javier, La muerte del rey: el ceremonial funerario de la monarquía española, 1500-1885, Madrid, Turner, 1990. 